\title{
Development of fragrant microcapsules for woven cotton fabric
}

\author{
Poonam Kumari ${ }^{1^{*}}$, Neelam M Rose ${ }^{2}$ and Saroj S. Jeet Singh ${ }^{2}$ \\ ${ }^{1}$ Department of Textile and Apparel Designing, CCS Haryana Agricultural University, Hisar-125004 (Haryana), \\ INDIA \\ ${ }^{2}$ I.C. College of Home Science, CCS Haryana Agricultural University, Hisar - 125004 (Haryana), INDIA \\ *Corresponding author. E-mail: minkusmile@gmail.com
}

Received: February 23, 2016; Revised received: February 9, 2017; Accepted: May 6, 2017

\begin{abstract}
A consumer-oriented twenty first century challenges garment and fabric producers to come up with innovations which result from the technological advancements to not only help in strengthening the existing product line but also to diversify and flourish in new areas. Many fragrant fabrics have been developed nowadays due to the reason of enjoying a healthy life style, and these novel products often possess additional functionalities which are good for human health. Not only does plant essential oil give off a pleasant smell but also the functions of antiseptic, antiphlogistic and emotional calming. In the present study, microencapsulation of geranium oil was carried out on cotton woven fabric. Geranium oil was selected as the core material and gum acacia as wall material for encapsulation using complex coacervation technique and ratio of $1: 4: 4$ of oil, gum and gelatin, at a temperature of $50^{\circ} \mathrm{C}$ with initial and final $\mathrm{pH} 4.5$ and 9.0 respectively was optimized for microencapsulation process. Microencapsulation helped in controlling the release rate of aroma and imparted durable fragrance finish on textiles.
\end{abstract}

Keywords: Fragranced textiles, Geranium oil, Microcapsule gel, Optimization

\section{INTRODUCTION}

The consumers' needs, demands and expectations of a healthier and more comfortable life are increasing everyday even when it comes to clothing. To achieve this simple but arduous aim, scientists, pharmacists, chemists and physician have tried over years and years to figure out new directions to prevent and combat diseases. In recent decades, people not only focus on using traditional medications and surgeries but also on other complementary therapies which lead to the quick development of natural therapies such as aromatherapy (Yuen and Annie, 2010). Essential oils which are basic ingredients of aromatherapy are effective to be as an alternative or complementary to conventional medical practices for conditions such as anxiety, depression and boosting cellular immune functions as many common essential oils have therapeutic properties like relive the pain, reduce stress and feel relaxed. Essential oils are the ethereal fraction obtained by physical means from a plant. These oils are also known as volatile, ethereal oils or simply as the 'oil of the plant' from which they were extracted. Oil is 'essential' in the sense that it carries a distinctive scent or essence of the plant. Essential oils and plant extracts are assumed to be ecologically sound and there is generally an absence of unwanted side effects from the use of essential oils (West and Hitchcock, 2014). As fragrances are volatile so they evaporate away and do not stay for long periods and are not resistant to wash. Therefore microencapsulation was found to be a solution to this problem. Microencapsulation is the process of surrounding or enveloping one substance within another substance on a very small scale, yielding capsules ranging from less than one micron to several hundred microns in size. The encapsulation efficiency of the microparticles or microsphere or microcapsule depends upon different factors like concentration of the polymer, solubility of polymer in solvent, rate of solvent removal, solubility of organic solvent in water etc. This new technology involves the preparation of a core material having the desired characteristics in extremely tiny amounts surrounded by shells of limited permeability. The active core material should be protected from the external environment by the employment of effective technologies (Hidekazu Yoshizawa, 2004). Hence, the main objective of this study was to standardize the process of geranium oil microencapsulation.

\section{MATERIALS AND METHODS}

In the present study, microcapsule gel was prepared using geranium oil, gum acacia and gelatin using complex coacervation technique (Bhat, 2012). Comparative analysis on the various aspects such as size of microcapsule, uniformity in distribution and wall of the microcapsules was done and a standard process of microencapsulation was developed with specific ratios at specific conditions of temperature and $\mathrm{pH}$. Wall material was used to encapsulate the core material. 


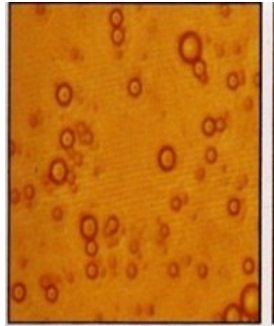

Rank 1 (1:4:4)

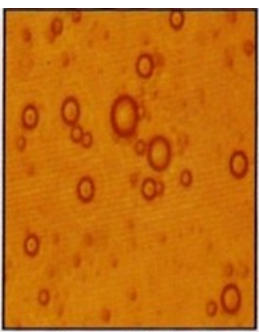

Rank- II (2:4:4)

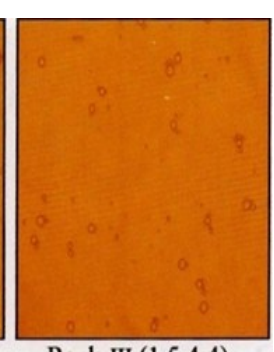

Rank-III (1.5:4:4)

Fig. 1. Microcapsules at optimized ratio of geranium oil.

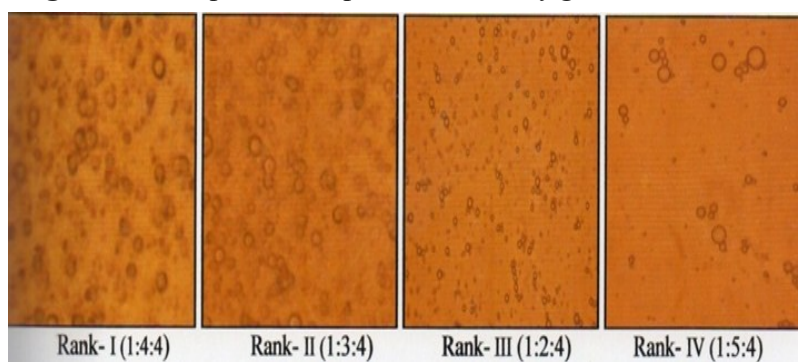

Fig. 2. Microcapsules at different ratio of gum acacia.

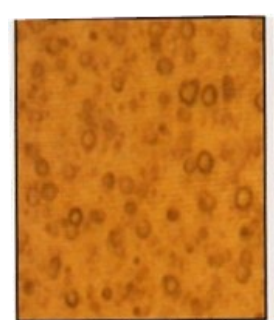

Rank- I (1:4:4)

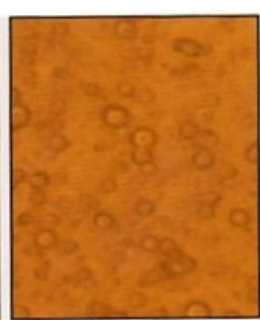

Rank- II (1:4:5)

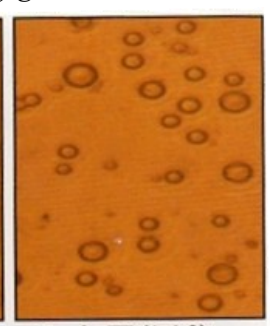

Rank- III (1:4:3)

Fig. 3. Microcapsules at different ratio of gelatin.

Gum acacia was used as a wall material since this is natural easily available wall material. Selection of core material was done keeping in mind the aroma and therapeutic effects of the oil. Hence, geranium oil was used as a core material.

Gum was taken as the wall material and essential oil as the core material. Gelatin is the common ingredient in all the processes of complex coacervation. Various concentrations of the raw material and conditions were optimized.

Standardization of preparation of microcapsules: The various variables of microencapsulation process i.e. ratio of oil, gum and gelatin, temperature and $\mathrm{pH}$ were optimized one by one. The basic recipe was modified by incorporating different amount of oil, gum and gelatin subjected to different ranges of temperature and

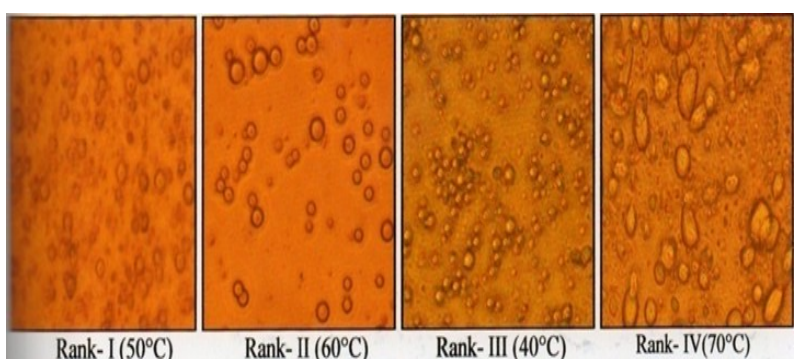

Fig. 4. Microcapsules at different temperature.

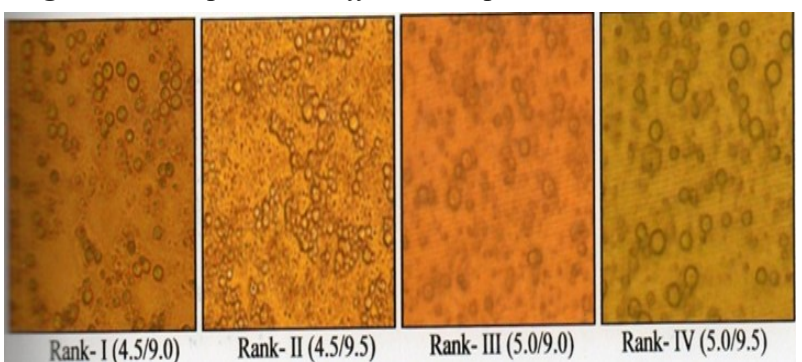

Fig. 5. Microcapsules at different initial and final $\mathrm{pH}$.

$\mathrm{pH}$ and the resultant precipitate obtained after each process was analyzed under inverted microscope to ensure the formation of microcapsules and images were captured. For optimization, comparative analysis of the images were done for various aspects. The combinations of concentrations of oil, gum and gelatin which produced the desired results were further subjected to optimization of the other variables. At a time the concentration of only one ingredient was varied and other ingredients and variables were kept constant. Microcapsule gel was prepared using the standardized recipe. Optimized ratio of gelatin was dissolved in warm water and was stirred at high speed for $10 \mathrm{~min}$. Optimized ratio of essential oil (core material) was added to the solution at optimized temperature and $\mathrm{pH}$ of the solution was set at optimized initial $\mathrm{pH}$. After that optimized ratio of gum acacia was dissolved in water and mixed with above solution. The whole solution was stirred at high speed for $20 \mathrm{~min}$ and temperature was lowered to $5^{\circ} \mathrm{C}$ for gel formation. The $\mathrm{pH}$ of the gel was set at optimized final $\mathrm{pH} .1 \mathrm{ml}$ of alcoholic formalin (17 percent) was added to the formed capsules (Shweta et al., 2012).

\section{RESULTS AND DISCUSSION}

Standardization of preparation of microcapsules:

Table 1. Optimization of ratio of geranium oil in microcapsule gel.

\begin{tabular}{|c|c|c|c|c|c|}
\hline \multirow{2}{*}{$\begin{array}{l}\text { Ratio of } \\
\text { Oil: gum: gelatin }\end{array}$} & \multirow{2}{*}{$\begin{array}{l}\text { Formation of } \\
\text { microcapsules }\end{array}$} & \multicolumn{3}{|c|}{$\begin{array}{r}\text { Parameters } \\
\end{array}$} & \multirow[t]{2}{*}{ Rank } \\
\hline & & $\begin{array}{c}\text { Size of micro- } \\
\text { capsules }\end{array}$ & $\begin{array}{c}\text { Uniformity in size and } \\
\text { distribution }\end{array}$ & Wall of microcapsules & \\
\hline $0.5: 4: 4$ & No & - & - & - & - \\
\hline $1: 4: 4$ & Yes & Medium & Good & Sharp and thick & $\mathrm{I}$ \\
\hline $1.5: 4: 4$ & Yes & Small & Good & Very thin & III \\
\hline $2: 4: 4$ & Yes & Large & Poor & Thick & II \\
\hline $2.5: 4: 4$ & No & - & & - & - \\
\hline $3: 4: 4$ & No & - & - & - & - \\
\hline
\end{tabular}


Table 2. Optimization of ratio of gum acacia in microcapsule gel.

\begin{tabular}{llcccc}
\hline Ratio of & Formation of & & Parameters & Rank \\
\cline { 3 - 5 } Oil: gum: gelatin & microcapsules & $\begin{array}{c}\text { Size of microcap- } \\
\text { sules }\end{array}$ & $\begin{array}{c}\text { Uniformity in size and } \\
\text { distribution }\end{array}$ & Wall of microcapsules & \\
\hline $1: 1: 4$ & No & - & - & - & - \\
$1: 2: 4$ & Yes & Very Small & Average & Thin & III \\
$1: 3: 4$ & Yes & Medium & Good & Thin & II \\
$1: 4: 4$ & Yes & Medium & Good & Sharp and thick & I \\
$1: 5: 4$ & Yes & Medium & Very poor & Thick & IV \\
$1: 6: 4$ & No & - & - & - & - \\
\hline
\end{tabular}

Oil ratio: 1

Table 3. Optimization of ratio of gelatin in microcapsule gel.

\begin{tabular}{|c|c|c|c|c|c|}
\hline \multirow{2}{*}{$\begin{array}{l}\text { Ratio of } \\
\text { Oil: gum: gelatin }\end{array}$} & \multirow{2}{*}{$\begin{array}{l}\text { Formation of } \\
\text { microcapsules }\end{array}$} & \multicolumn{3}{|c|}{ Parameters } & \multirow[t]{2}{*}{ Rank } \\
\hline & & $\begin{array}{c}\begin{array}{c}\text { Size of microcap- } \\
\text { sules }\end{array} \\
\end{array}$ & $\begin{array}{c}\begin{array}{c}\text { Uniformity in size and } \\
\text { distribution }\end{array} \\
\end{array}$ & Wall of microcapsules & \\
\hline $1: 4: 1$ & No & - & - & - & - \\
\hline $1: 4: 2$ & No & - & - & - & - \\
\hline $1: 4: 3$ & Yes & Small & Average & Thin & III \\
\hline $1: 4: 4$ & Yes & Medium & Good & Thick & $\mathrm{I}$ \\
\hline $1: 4: 5$ & Yes & Medium + large & Poor & Sharp \& thick & II \\
\hline 1:4:6 & No & - & - & - & - \\
\hline
\end{tabular}

Oil: gum- 1:4

Optimization of the proportion of geranium oil in microcapsule gel: Geranium oil forms the core material of the microcapsule and is basically responsible for the both i.e. fragrance and therapeutic effect. Microcapsule gel was prepared using different ratio of geranium oil i.e. $0.5,1.0,1.5,2.0,2.5$ and 3.0 . The gel was observed under inverted microscope to ensure the presence of microcapsules. The ratio of geranium oil optimized on the basis of visual assessment of three parameters i.e. size of microcapsules, uniformity in size and distribution and wall of microcapsules. The data presented in Table 1 and visual assessment of microcapsule gel indicate that though microcapsules were formed in three ratio of oil, gum and gelatin i.e. 1:4:4, 1.5:4:4, 2:4:4 respectively (Fig. 1) but the microcapsules formed in the ratio of 1:4:4 were medium sized, good uniformity in size and the wall was also sharp and thick as compared to the capsules formed at other ratios i.e. 1.5:4:4, $2: 4: 4$. Therefore, the ratio of geranium oil i.e. 1 was used for further optimization to achieve the best results. More amount of oil led to larger size of capsules and in some cases no gel formation occurred as the gum and gelatin were not able to form wall around it. The above results were supported by the finding of Agarwal and Goel (2010), who concluded that at the ratio of oil 1 , medium size microcapsules were formed.

Optimization of ratio of gum acacia in microcapsule gel: Gum acacia forms the wall/ outer core of the microcapsule and protects the oil from abrasion, sunlight and biodegradation thus provides a controlled release to the oil. Microcapsule gel was prepared using different ratio of gum acacia i.e. 1, 2, 3, 4, 5 and 6. The data presented in Table 2 and visual assessment of microcapsule gel (Fig. 2) indicates that microcapsules were formed in four ratios of oil, gum and gelatin i.e. 1:2:4, $1: 3: 4,1: 4: 4$ and 1:5:4. The microcapsules formed in the ratio of $1: 4: 4$ were medium sized, had good uniformity in size and distribution and the wall was also sharp and thick as compared to the capsules in the other three ratios i.e. 1:2:4, 1:3:4 and 1:5:4, as these were very small to medium in size, having average to very poor uniformity in size and distribution, thin to thick walls of capsules. Therefore, the ratio 4of gum acacia was optimized. When the amount of gum was increased the walls of the capsules started rupturing and

Table 4. Optimization of temperature for microencapsulation.

\begin{tabular}{|c|c|c|c|c|c|}
\hline \multirow{2}{*}{$\begin{array}{l}\text { Temperature } \\
\left({ }^{\circ} \mathrm{C}\right)\end{array}$} & \multirow{2}{*}{$\begin{array}{l}\text { Formation of } \\
\text { microcapsules }\end{array}$} & \multicolumn{3}{|c|}{ Parameters } & \multirow[t]{2}{*}{ Rank } \\
\hline & & Size of microcapsules & $\begin{array}{c}\text { Uniformity in size and } \\
\text { distribution }\end{array}$ & Wall of microcapsules & \\
\hline 30 & No & - & - & - & - \\
\hline 40 & Yes & Small & Good & Thick & III \\
\hline 50 & Yes & Medium & Good & Thick & I \\
\hline 60 & Yes & Medium & Poor & Sharp and thick & II \\
\hline 70 & Yes & Very large & Average & Ruptured & IV \\
\hline 80 & No & - & - & - & - \\
\hline
\end{tabular}

Oil: gum: gelatin $-1: 4: 4$ 
Table 5. Formation of microcapsules at different $\mathrm{pH}$.

\begin{tabular}{|c|c|c|c|c|c|c|c|}
\hline \multirow[t]{2}{*}{ Initial Ph / Final pH } & 4.0 & 4.5 & 5.0 & 5.5 & 6.0 & 6.5 & 7.0 \\
\hline & \multicolumn{7}{|c|}{ Formation of microcapsules } \\
\hline 7.0 & $\mathrm{x}$ & $\mathrm{X}$ & $\mathrm{X}$ & $\mathrm{x}$ & $\mathrm{X}$ & $\mathrm{x}$ & $\mathrm{X}$ \\
\hline 7.5 & $\mathrm{x}$ & $\mathrm{X}$ & $\mathrm{X}$ & $\mathrm{x}$ & $\mathrm{X}$ & $\mathrm{x}$ & $\mathrm{X}$ \\
\hline 8.0 & $\mathrm{x}$ & $\mathrm{X}$ & $\mathrm{X}$ & $\mathrm{x}$ & $\mathrm{X}$ & $\mathrm{x}$ & $\mathrm{X}$ \\
\hline 8.5 & $\mathrm{x}$ & $\mathrm{X}$ & $\mathrm{X}$ & $\mathrm{x}$ & $\mathrm{X}$ & $\mathrm{x}$ & $\mathrm{X}$ \\
\hline 9.0 & Formed & Formed & Formed & $\mathrm{x}$ & $\mathrm{X}$ & $\mathrm{x}$ & $\mathrm{X}$ \\
\hline 9.5 & Formed & Formed & Formed & $\mathrm{x}$ & $\mathrm{X}$ & $\mathrm{x}$ & $\mathrm{X}$ \\
\hline 10.0 & Formed & Formed & Formed & $\mathrm{x}$ & $\mathrm{X}$ & $\mathrm{x}$ & $\mathrm{X}$ \\
\hline
\end{tabular}

Oil: gum: gelatin-1:4:4, temperature- $50^{\circ} \mathrm{C}$

Table 6. Optimization of $\mathrm{pH}$ for microencapsulation.

\begin{tabular}{llcccc}
\hline pH & Formation of \\
initial/final & microcapsules & & Parameters & Rank \\
\cline { 3 - 5 } & & Size of microcapsules & $\begin{array}{c}\text { Uniformity in size and } \\
\text { distribution }\end{array}$ & Wall of microcapsules & \\
\hline $4.0 / 9.0$ & Yes & Small & Average & Very thin & VI \\
$4.0 / 9.5$ & Yes & Small & Poor & Thin & VII \\
$4.0 / 10.0$ & Yes & Very small & Poor & Very thin & IX \\
$4.5 / 9.0$ & Yes & Medium & Good & Sharp and thick & I \\
$4.5 / 9.5$ & Yes & Medium & Average & Sharp and thick & II \\
$4.5 / 10.0$ & Yes & Medium & Poor & Thin & VI \\
$5.0 / 9.0$ & Yes & Medium & Average & Thick & III \\
$5.0 / 9.5$ & Yes & Large + medium & Average & Thick & IV \\
$5.0 / 10.0$ & Yes & Small & Average & Thin & V \\
\hline
\end{tabular}

lumps were formed due to disproportionate ratio of oil and gum. Danfeng et al. (2012) also prepared olive oil microcapsules by complex cocervation and reported that microcapsules were formed at core to wall ratio $1: 3$, as ratio more than this formed large size of capsules and wall of capsules started rupturing.

Optimizations of ratio of gelatin in microcapsule gel: Gelatin is a common ingredient of complex coacervation process and gives best results with gum acacia and oil. Microcapsule gel was prepared using different ratio of gelatin i.e. $1,2,3,4,5$ and 6 . The gel was observed under inverted microscope to check the presence of microcapsules. The ratio of gelatin was optimized on the basis of visual assessment on three parameters i.e. size of microcapsules, uniformity in size and distribution and wall of microcapsules.

The data presented in Table 3 and visual assessment of microcapsule gel indicates that microcapsules were formed in the ratio of oil, gum and gelatin i.e. 1:4:3, 1:4:4 and 1:4:5 (Fig. 3). The microcapsules formed in the ratio of 1:4:4 were medium sized, had good uniformity in size and distribution and the wall was thick as compared to the capsules in the ratio of 1:4:3 and $1: 4: 5$, which were small in size, average uniformity, thin walls and medium+ larger in size with poor uniformity, sharp and thick wall of capsules respectively. Therefore the ratio 4 of gelatin was optimized. The results are in accordance with the Bhat (2012) who reported that gum acacia: lemongrass essential oil: gelatin of ratio $2: 1: 4$ was the most appropriate ratio for formation of microcapsules of essential oil on cotton fabric.
Optimization of temperature for microencapsulation: For optimization of temperature microencapsulation process was carried out at six different temperatures i.e. $30,40,50,6070$ and $80{ }^{\circ} \mathrm{C}$. The gel was observed under inverted microscope to check the presence of microcapsules. The temperature was optimized on the basis of visual assessment of three parameters i.e. size of microcapsules, uniformity in size and distribution and wall of microcapsules.

It is clear from Table 4 and visual evaluation (Fig. 4) that at 30 and $80{ }^{\circ} \mathrm{C}$ temperature microcapsules were not formed. The microcapsules formed at $50{ }^{\circ} \mathrm{C}$ were medium sized, had good uniformity in size and distribution and the wall was also thick as compared to microcapsules formed at $60{ }^{\circ} \mathrm{C}$ were also medium sized, poor distribution and sharp and thick walls but the capsules formed at $40 \& 70{ }^{\circ} \mathrm{C}$ were small sized, had good uniformity, thick walls and very large in size, average uniformity with ruptured walls respectively. Hence $50{ }^{\circ} \mathrm{C}$ temperature was optimized for microencapsulation as higher temperature led to increase in evaporation of essential oils resulting in rupturing of walls and size of microcapsule increases. The results obtained are in line with the findings of Ganesan et al. (2012) applied microcapsules on single jersey knitted fabric and found that $40-50{ }^{\circ} \mathrm{C}$ temperature was suitable for microencapsulation as the increased temperature led to increase in size of microcapsules resulting in wall rupture.

Optimization of $\mathrm{pH}$ for microencapsulation: The role of $\mathrm{pH}$ is very important in microencapsulation as it is responsible for phase separation that leads to capsule 
formation. To optimize initial $\mathrm{pH}$ and the final $\mathrm{pH}$, microcapsule gel was initially set at $\mathrm{pH} 4.0,4.5,5.0$, 5.5, 6.0, 6.5 and 7.0. After the completion of microencapsulation process and gel formation the final $\mathrm{pH}$ of the gel was set at 7.0, 7.5, 8.0, 8.5, 9.0, 9.5 and 10 . Microencapsulation was carried out with optimized ratio of oil: gum: gelatin, temperature and $\mathrm{pH}$.

Table 5 reveals that microcapsules were formed only when the initial $\mathrm{pH}$ ranged from 4 to 5 and final $\mathrm{pH}$ ranged from 9 to 10 . The $\mathrm{pH}$ range other than this was not suitable for phase separation and microcapsule formation with geranium oil.

It is evident from Table 6 and visual analysis of microcapsule gel that the microcapsules formed at initial $\mathrm{pH}$ 4.5 and final $\mathrm{pH} 9.0$ were medium in size with good uniformity in size and distribution and thick and sharp walls (Fig. 5). Therefore these were optimized as optimum initial and final $\mathrm{pH}$ for microencapsulation process for the preparation of geranium oil capsules. The findings of Sukumar and Lakshmikantha (2010) also support the results as they reported that microcapsules were formed at initial $\mathrm{pH}$ ranged from 4-4.5 and final $\mathrm{pH}$ to be 9 for application on bleached cotton fabric.

Thus it can be concluded that best results were obtained when the ratio of oil: gum: gelatin was $1: 4: 4$, temperature $50{ }^{\circ} \mathrm{C}$, initial $\mathrm{pH} 4.5$ and final $\mathrm{pH} 9.0$. The microcapsules formed with these optimized conditions were medium sized, had good uniformity in size and distribution with sharp and thick wall of capsules. The above results are accordance with the findings of $\mathrm{Fa}$ bien et.al. (2009), who reported that a temperature of $60{ }^{\circ} \mathrm{C}$ and $\mathrm{pH} 9$ was suitable for formation of medium size microcapsules of geranium oil.

\section{Conclusion}

The proportion of essential oil, gumand gelatin in the ratio $1: 4: 4$ at temperature $50{ }^{\circ} \mathrm{C}$ with initial $\mathrm{pH} 4.5$ and final $\mathrm{pH} 9.0$ were optimum variable as the prepared microcapsules were medium sized, had good uniformity in size and distribution and sharp and thick walls of capsules. High temperature leads to rupturing of wall hence increase the capsule size. Medium sized microcapsules with sharp and thick walls and good uniformity in size and distribution was obtained at temperature $50{ }^{\circ} \mathrm{C}$. Microcapsules were formed only when the initial $\mathrm{pH}$ was set at acidic $\mathrm{pH}$ between 4-5 as phase separation takes place at this $\mathrm{pH}$ only. Thus, it can be concluded that these optimized variables can be used to prepare the geranium oil microcapsules for application on fabrics for the development of fragrant textiles.

\section{REFERENCES}

Agarwal, M. and Goel, A. (2010). Microencapsulation of citronella oil for aromatherapic textiles. $23^{\text {rd }}$ National Convection of Textiles Engineers. March 26-27. New Delhi.

Bhat, L. (2012). Microencapsulation of essential oil on cotton. Unpublished Master's Thesis. CCS Haryana Agricultural University, Hisar.

Danfeng, Y., Wenjing, Q. and Qiuyu, L. G. (2012). Preparation and properties of olive oil microcapsules. $J$. of Fiber Bioeng. and Info., 5 (1): 67-76

Fabien, S., Eric, D., Serge, B. and Pascal, R. (2009). Application of contact angle measurement to the manufacture of textiles containing microcapsules. Textile R. J., 9 (13): 1202-1212

Ganesan, P., Selvi, C. T. and Ramchandran, T. (2012). Microencapsulation of copper enriched herbals for curative garments. Indian J. of Traditional Knowledge, 11 (3): $532-536$

Hidekazu Yoshizawa (2004). Trends in microencapsulation research. KONA, $22: 22-31$

Sukumar, N. and Lakshmikantha, C. B. (2010). Methods of encapsulation and their evaluation of the natural aromatic oils in textile material. Indian J. of Applied Sci., 56(11): 56-69

Shweta, P., Maya, K. S., Bhattacharyya, A. and Argillier, J. F. (2003). Micro-encapsulation by complex coacervation: Influence of surfactant. J. of Polymer Inst., 52: 644 $-647$

West, A. J. and Hitchcock, A. K. E. (2014). A critical review of aroma therapeutic applications for textiles. $J$. of $T$. and $A$ Tech. and Management, 9(1): 48-61

Yuen, C. W. M. and Annie, Y. U. (2010). Fragrant fabric for intimate apparel produced by host-guest interactions of $\mathrm{TiO}^{2}$ modified with $\beta$-Cyclodextrins. Unpublished Bachelor of Arts (Honours) Thesis, Institute of Textiles and Clothing, Polytechnic University, Hong Kong 